\title{
Diagnóstico e Tratamento das Complicações Vasculares em Harmonização Orofacial: revisão e atualização da literatura
}

\author{
Diagnosis and Treatment of Vascular Complications in Orofacial Harmonization: literature \\ review and update
}

\section{Diagnóstico y Tratamiento de las Complicaciones Vasculares en la Armonización Oro Facial: revisión y actualización de la literatura}

Kledson Lopes Barbosa ${ }^{1,2 *}$, Luiz Arthur Barbosa da Silva ${ }^{1}$, Christiani Lozany Ferreira de Lima Araújo $^{3}$, Gisele Rosada Dônola Furtado ${ }^{2,4}$, Célia Marisa Rizzatti Barbosa ${ }^{2,4}$, Esteban Emilio Benitez Martin².

\section{RESUMO}

Objetivo: Identificar as intercorrências vasculares mais prevalentes pela injeção de ácido hialurônico em harmonização orofacial e descrever as estratégias de intervenção para tratamento dessas complicações. Revisão bibliográfica: A embolização e compressão vascular são as formas mais graves de intercorrência na harmonização orofacial ocasionadas por grandes quantidades de material injetado, desenvolvendo-se quadros de isquemia, necrose e até mesmo cegueira. A aplicação hialuronidase ainda continua off label para degradar ácido hialurônico nos casos de oclusão/compressão vascular, no entanto, esta enzima é até o momento a única opção eficiente para reverter essas complicações, onde seu efeito é incontestável nas melhores evidências disponíveis. Apesar dos preenchedores de ácido hialurônico ser bem tolerados, a compreensão adequada dos critérios clínicos e protocolos de tratamento, domínio e competência técnica para correção das intercorrências são elementos fundamentais para segurança do ácido hialurônico nas harmonizações orofaciais. Considerações finais: O conhecimento da anatomia, o planejamento adequado do tratamento, bem como o diagnóstico precoce e tratamento correto das complicações vasculares (compressão e embolização arterial, necrose, cegueira) faz com que procedimentos em harmonização facial tenham resultados previsíveis e eficientes.

Palavras-chave: Ácido hialurônico, Hialuronidase, Isquemia, Necrose, Cegueira.

\begin{abstract}
Objective: Identify the most prevalent vascular complications caused by the injection of hyaluronic acid in orofacial harmonization and describe the intervention strategies to treat these complications. Bibliographic review: Embolization and vascular compression are the most serious forms of intercurrence in orofacial harmonization caused by large amounts of injected material, developing ischemia, necrosis and blindness. The application of hyaluronidase is still off-label to degrade hyaluronic acid in cases of vascular occlusion/compression, however, this enzyme is so far the only efficient option to reverse these complications, where its effect is incontestable in the best available evidence. Although hyaluronic acid fillers are well tolerated, an adequate understanding of clinical criteria and treatment protocols, mastery and technical competence to correct complications are essential elements for the safety of hyaluronic acid in orofacial harmonization. Final considerations: The knowledge of anatomy, the proper planning of treatment, as well as the early diagnosis and correct treatment of vascular complications (artery compression and embolization, necrosis, blindness) make facial harmonization procedures have predictable and efficient results.
\end{abstract}

Key words: Hyaluronic acid, Hyaluronidase, Ischemia, Necrosis, Blindness.

1 Centro Universitário Maurício de Nassau (UNINASSAU), Maceió - AL. *E-mail: kledsonlopesb@gmail.com

2 Associação Internacional de Harmonização Orofacial (ASSIHOF), São Paulo - SP.

${ }^{3}$ Instituto de Pós-Graduação (IPOG), Maceió - AL.

${ }^{4}$ Centro Universitário Uningá Maringá, Maringá - PR. 


\section{RESUMEN}

Objetivo: Identificar las complicaciones vasculares más frecuentes por la inyección de ácido hialurónico en armonización orofacial y describir las estrategias de intervención para el tratamiento de estas complicaciones. Revisión bibliográfica: La embolización y la compresión vascular son las formas más graves de complicación en la armonización orofacial causadas por grandes cantidades de material inyectado, desarrollandose cuadros de isquemia, necrosis e incluso ceguera. La aplicación de hialuronidasa se encuentra aún off label para degradar el ácido hialurónico en casos de oclusión/compresión vascular, sin embargo, esta enzima es hasta ahora la única opción eficiente para revertir estas complicaciones, donde su efecto es innegable según la mejor evidencia disponible. Aunque los rellenos de ácido hialurónico son bien tolerados, el entendimiento adecuado de los criterios clínicos y protocolos de tratamiento con el dominio y la competencia técnica para corregir las complicaciones, son elementos esenciales para la seguridad del uso del ácido hialurónico en las armonizaciones orofaciales. Consideraciones finales: El conocimiento de la anatomía, la adecuada planificación del tratamiento, así como el diagnóstico precoz y la correcta resolución de posibles complicaciones (compresión y embolización arterial, necrosis, ceguera), hacen que los procedimientos de armonización facial tengan resultados predecibles y eficientes.

Palabras clave: Ácido hialurónico, Hialuronidasa, Isquemia, Necrosis, Ceguera.

\section{INTRODUÇÃO}

O uso dos preenchedores faciais foi impulsionado na última década com o advento das especialidades em harmonização orofacial e, a partir de então, vem alcançando cada vez mais destaque nos tratamentos não cirúrgicos de rejuvenescimento facial. Suas aplicações permitem reacomodação dos tecidos flácidos da face e estímulo à produção de colágeno para corrigir as características perdidas do contorno facial comuns no envelhecimento (MUNDADA P, et al., 2017).

As características ideais do ácido hialurônico são aquelas que conferem meia-vida prolongada, resistência à degradação e biocompatibilidade ao tecido implantado, serem atóxicos e não reativo a matriz tecidual e que se agreguem às estruturas mantendo sua forma e consistência (WORTSMAN X, 2012). Além disso, é importante que estes produtos não migrem de uma região para outra e demonstrem fácil remoção nos casos de intercorrências imediatas ou tardias (DÍAZ CPG, 2019).

A injeção de preenchedores em regiões orofaciais pode produzir complicações graves pela grande complexidade do aporte sanguíneo existente na face, sendo a embolização um exemplo disto. Esta complicação é decorrente, ou da aplicação do ácido hialurônico dentro de um vaso sanguíneo, ou pela compressão externa destes devida à expansão do preenchedor, que oblitera o suprimento sanguíneo da região. Prevenir ou detectar estes casos precocemente pode ser possível por meio do uso do ultrassom, uma vez que, através deste equipamento, é possível visualizar as diferentes camadas dos tecidos da pele, dos tecidos adjacentes e os agentes de preenchimento (SCHELKE LW, et al., 2010).

Diante do exposto, o presente constructo teve como objetivo realizar uma revisão bibliográfica do tipo narrativa acerca das intercorrências vasculares pela injeção intravascular de ácido hialurônico nos procedimentos estéticos de harmonização orofacial.

\section{REVISÃO BIBLIOGRÁFICA}

\section{Propriedades ultrassonográficas dos preenchedores formulados a base de ácido hialurônico}

Levando em consideração à ecogenicidade dos aparelhos de ultrassonografia, os materiais preenchedores, através da sua reação no tecido, poderão ser visualizados como hiperecoico (imagem branca na tela do dispositivo), hipoecóico (cinza na tela) e anecoico (preto na tela). Os tecidos são isoecogênicos, e é isso o que os difere das estruturas sintéticas (SCHELKE LW, et al., 2018). As moléculas de água sequestradas pelo ácido hialurônico não reflete nas ondas sonoras do ultrassom, e por essa razão é detectado como uma imagem preta ecogênica ou hipoecóico - cinza claro (KOHN JC, et al., 2013). 
Os exames ultrassonográficos dos planos preenchidos com ácido hialurônico revelam imagens anecóicas, subcutâneas e semelhantes à pseudocistos sem revestimento epidérmico ou detritos (MICHEELS P, et al., 2017). No entanto, quando o preenchimento é realizado com a mistura de ácido hialurônico mais lidocaína, as propriedades das imagens podem apresentar ecos ou detritos internos dentro dos pseudocistos (DíAZ CPG, 2019).

\section{Seleção de agulhas para injeção de preencherdores dérmicos}

As agulhas de menor calibre podem implicar em eventos adversos por às vezes, serem menos espessas do que o lúmen de um vaso sanguíneo. $O$ fato é que a pressão exercida sobre a injeção se transfere para o fluxo sanguíneo e facilita o deslocamento dos êmbolos para outras áreas de maior pressão. Apesar de ainda haver muitas controvérsias sobre o uso de agulhas de menor e maior calibre, recomenda-se o uso de cânulas mais calibrosas, visto que estas diminuem os riscos de embolização arterial (KOH IS e LEE W, 2019).

Avaliações de canulação percutânea experimental de artérias supraorbitais, revelaram diâmetro de 1,8 $\mathrm{mm}$ para a artéria supratroclear, e 0,86 mm para artéria supraorbital. Um estudo anatômico da embolia da artéria oftálmica após injeção de preenchedor revelaram que as artérias supratroclear, supraorbital, dorsal nasal possuem diâmetro em torno de $1 \mathrm{~mm}$ (SCHWENN OK, et al., 2005; WU S, et al., 2017). Estes estudos reforçam a ideia da utilização de cânulas com maior calibre a fim de evitar a embolização arterial, como também da quantidade de material preenchedor a ser depositado nessas regiões, quando julgado extremamente necessário. Existem vários diâmetros de cânulas disponíveis, no entanto, a escolha delas deve estar relacionada ao seu diâmetro relativo versus diâmetro da artéria conforme visualizado na figura abaixo, a qual foi desenvolvida no Microsoft PowerPoint $2013^{\circledR}$ (Figura 1).

Figura 1 - Comparação entre o diâmetro arterial e diâmetro das cânulas 30G, 23G e 20G.

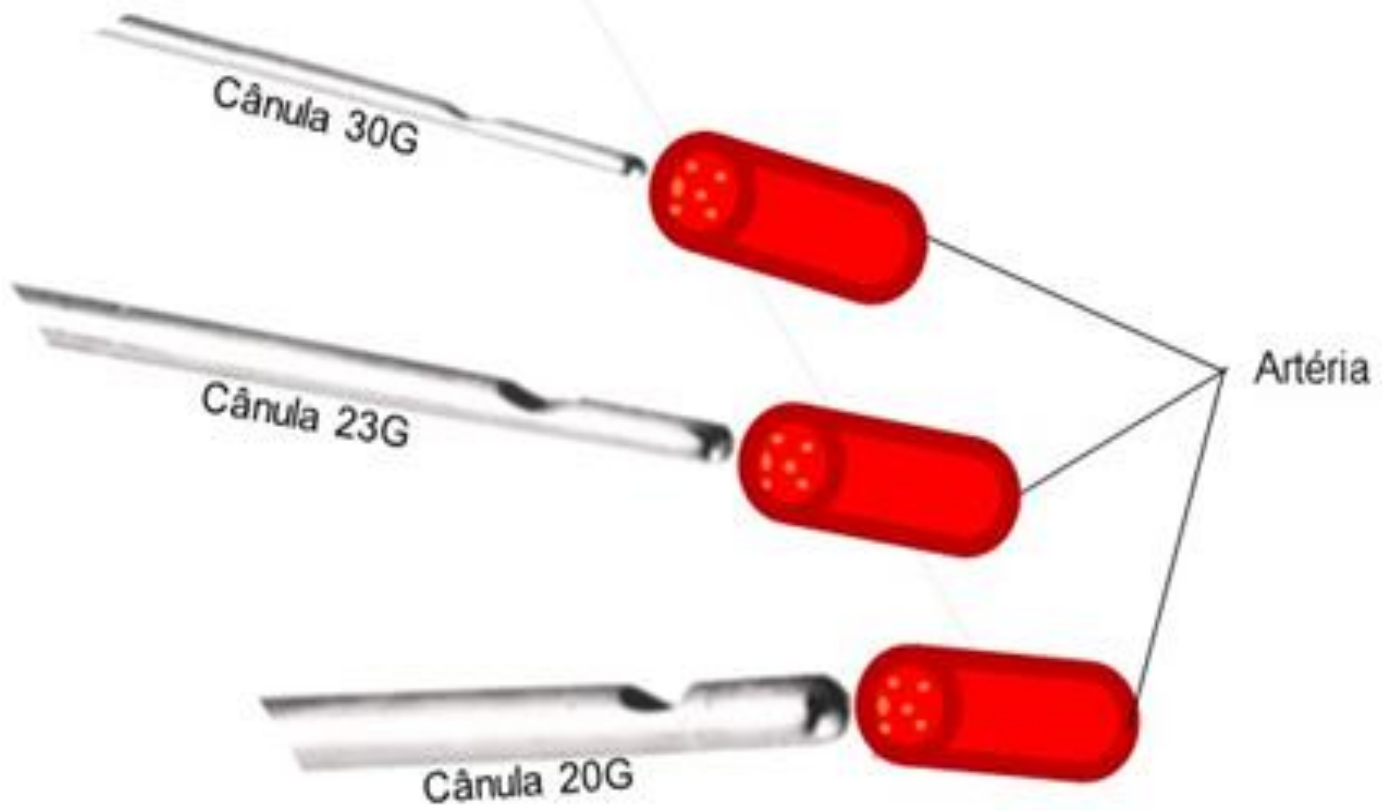

Fonte: Barbosa KL, et al., 2021.

A segurança em harmonização orofacial esclarece que os fatores predisponentes a embolização das artérias de suprimento sanguíneo da visão e do cérebro incluem: extremidade da agulha dentro de um ramo da artéria carótida interna no momento em que o material preenchedor está sendo depositado, pela pressão de injeção superior à pressão arterial e quantidade de carga maior que o volume arterial para cobrir a artéria central da retina. A artéria supraorbital, supratroclear e dorsal nasal são ramos da artéria carótida interna e constituem importantes pontos de atenção para preenchimento na região da face. Portanto, quando se opta em realizar o preenchimento nessas regiões, deve ser realizado apenas por injetores experientes $(\mathrm{KOH} I S$ e LEE W, 2019). 
Portanto, as estratégias mais seguras para prevenir intercorrências relacionadas ao ácido hialurônico na face incluem o uso de cânulas, teste de aspiração negativa anteriormente a injeção do material preenchedor, injeção lenta do material, menor volume do material em uma única sessão e injeções em regiões mais superficiais (BELEZNAY K, et al., 2015; DELORENZI C, 2017).

Aspirar à seringa antes de injetar o material preenchedor é altamente necessário para verificar se a ponta da agulha está dentro ou fora do vaso sanguíneo. Quando nenhum sinal de sangue surge durante o teste de aspiração, acredita-se que haja segurança para injetar o material preenchedor. Por outro lado, se houver presença de sangue durante a aspiração o procedimento deve ser prontamente abortado. As evidências sugerem alta especificidade para o teste de aspiração, porque a aspiração de sangue frequentemente indica que a agulha está dentro do vaso. No entanto, o risco de injeção intravascular não pode ser ignorado mesmo quando não houver sinais de sangue, porque podem existir casos de resultados falso-negativos (VAN LOGHEM JAJ, et al., 2017).

Realizar o teste de aspiração com uma seringa ainda cheia de ácido hialurônico aparentemente é bastante delicado porque pode diminuir a sensibilidade do teste, uma vez que uma seringa nova possui apenas $0,1 \mathrm{~mL}$ de pressão negativa e isso pode ocasionar resultados falso-negativos quando comparado, por ex., a uma seringa com $0,5 \mathrm{~mL}$ de pressão negativa. Esses aspectos podem influenciar diretamente entre as diferenças da injeção intravascular e extravascular (VAN LOGHEM JAJ, et al., 2017).

\section{Intercorrências decorrentes da injeção de ácido hialurônico}

O ácido hialurônico injetado acidentalmente no interior de um vaso desencadeia reações de irritabilidade e indução de importantes respostas inflamatórias na parede dos vasos. Sendo assim, nos casos de embolização arterial, verifica-se inflamação no tecido de revestimento, com consequente espasmo das conexões anastomóticas em torno do perímetro anatômico com o objetivo de restringir a necrose, desde que estes vasos anastomosados sejam de calibre reduzido (ASHTON MW, et al., 2018; TAYLOR GI, et al., 2017).

Os locais comumente preenchidos por ácido hialurônico incluem área perioral, periocular, malar, linhas de marionete, glabela e lábios (MUNDADA P, et al., 2017). Entretanto, complicações podem surgir por técnicas mal executadas originando necrose cutânea e até mesmo cegueira devido à embolização vascular (IWAYAMA T, et al., 2018).

A cegueira pode ocorrer após injeção de ácido hialurônico e constitui um problema severo da embolização da artéria central da retina. Nesse caso a pressão de injeção do material ultrapassa a pressão arterial e move o material para as artérias oftálmicas ou artérias cerebrais. Após liberação da pressão do embolo, o sangue retornará seu fluxo empurrando o produto para a artéria central da retina, interrompendo assim o suprimento de sangue para o nervo óptico (TOWNSHEND A, 2016). Além disso, casos extensos de obstrução vascular também podem levar à embolia cerebral causando danos neurológicos (KOH IS e LEE W, 2019).

A fim de explorar a fisiopatologia da cegueira causada por preenchedores dérmicos, foi realizado um inquérito por meio de 98 casos de cegueira descritos na literatura entre 1906 a 2015. Por meio deste estudo pode-se perceber que $38,8 \%$ dos casos de cegueira estavam relacionados ao preenchimento na região de glabela, $25,5 \%$ a região nasal, $13,3 \%$ ao sulco nasolabial e $12,2 \%$ relacionados à fronte. Ademais, não se encontrou registros de tratamento eficaz para esta complicação e os pacientes não relataram melhora do quadro (BELEZNAY K, et al., 2015).

A isquemia geralmente está associada à dor e esbranquiçamento da pele que não são compatíveis com o tratamento estético. Já os hematomas causados pela oclusão de um vaso estarão associados à dor, diferenciando-se de hematomas leves devido ao hematoma dos tecidos (KASSIR R, et al., 2011). Um fator que pode atrasar o diagnóstico é o uso de anestésico tópico e/ou injetáveis, assim como o uso de preenchedores com lidocaína, os quais inibem a dor, um sintoma da embolização (HWANG CJ, PERRY JF, 2018).

A injeção de ácido hialurônico no periósteo da prega nasolabial, para preenchimento dos sulcos nasogenianos é a principal queixa dos pacientes é um procedimento que merece muita atenção, uma vez que 
existem muitas variações anatômicas nesta região (VEDAMURTHY M e VEDAMURTHY A, 2008). Os ramos da artéria facial são responsáveis por fornecer sangue para base alar, e o suprimento de sangue nessa região pode ser comprometido pela injeção intravascular de ácido hialurônico, ocasionando embolias vasculares, e, consequentemente, um quadro grave de necrose cutânea nas asas nasais (BELEZNAY K, et al., 2015).

A compressão vascular se sustenta nos preceitos de que ao se preencher uma região de pequeno espaço com grande volume de material preenchedor em uma região cicatrizada, ou com sangramento intradérmico, ou com edema, pode ocasionar a oclusão da vasculatura local e como consequência, a isquemia (LIMA VGF, et al., 2019).

\section{Diagnóstico da isquemia e degradação do ácido hialurônico com hialuronidase}

O diagnóstico da isquemia se baseia na determinação clínica visual da área superficial do tecido isquêmico. Por meio do exame da pele, se realiza pressão sobre a região isquêmica para avaliar o reabastecimento capilar, como ilustrado a imagem abaixo, a qual foi desenvolvida no Microsoft PowerPoint $2013^{\circledR}$ (Figura 2). Esta técnica de diagnóstico se baseia em comprimir a pele da região afetada com, p. ex., um cabo de tesoura de sutura, até 5 segundos para verificar o tempo de reabastecimento capilar (Figura 2A). Nos casos em que houver deposição de ácido hialurônico intra-arterial, o sangue será impedido de circular livremente no interior do vaso, e não haverá reabastecimento sanguíneo da região, mantendo a região com aparência esbranquiçada (Figura 2B) (DELORENZI C, 2017).

Figura 2 - Exame de compressão da pele para avaliação de processos isquêmicos.
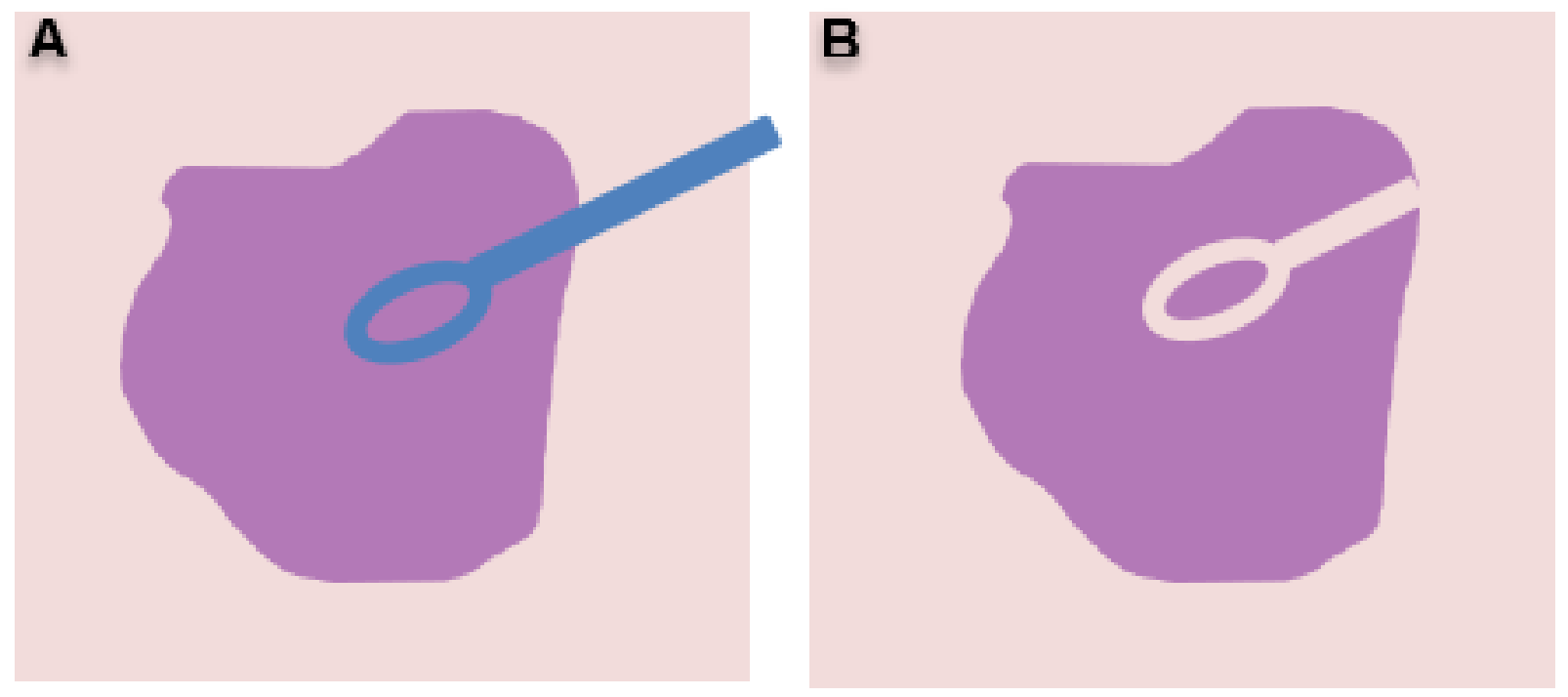

Fonte: BARBOSA KL, et al., 2021.

A isquemia geralmente aparece imediatamente à injeção do ácido hialurônico dando a pele um aspecto de branqueamento imediato. Esse quadro é acompanhado por dor persistente que não se limita ao local de aplicação do preenchedor e se irradia às áreas adjacentes. A coloração esbranquiçada evolui para um padrão de coloração de livedo (linhas vermelho-azuladas irregulares). Horas depois, a pele desenvolve um padrão de coloração roxo-azulada e enegrecida, podendo surgir pequenas vesículas semelhantes às vesículas herpéticas, que se rompem e produzem descontinuidade da pele e ulceração local (BRAVO et al., 2015).

Nos casos de compressão arterial e embolização causada por injeção acidental de ácido hialurônico dentro da artéria (Figura 3), o clínico tem como primeira opção de tratamento a injeção de hialuronidase, uma enzima mucolítica que age especificamente hidrolisando as ligações glicosídicas do ácido hialurônico (Figura 4), as figuras abaixo foram desenvolvidas no Microsoft PowerPoint 2013 ${ }^{\circledR}$. No entanto, seu uso deve ser precedido por teste de sensibilidade, uma vez que a mesma pode desencadear um processo alérgico (BELEZNAY K, et al., 2015; KIM MS, et al., 2015). Nesse sentido, a reação alérgica à hialuronidase deve fazer parte do 
diagnóstico diferencial quando ocorre o surgimento de eritema focal e inchaço após sua administração no teste de sensibilidade (KIM MS, et al., 2015).

Figura 3 - Obliteração arterial pela injeção acidental de ácido hialurônico.

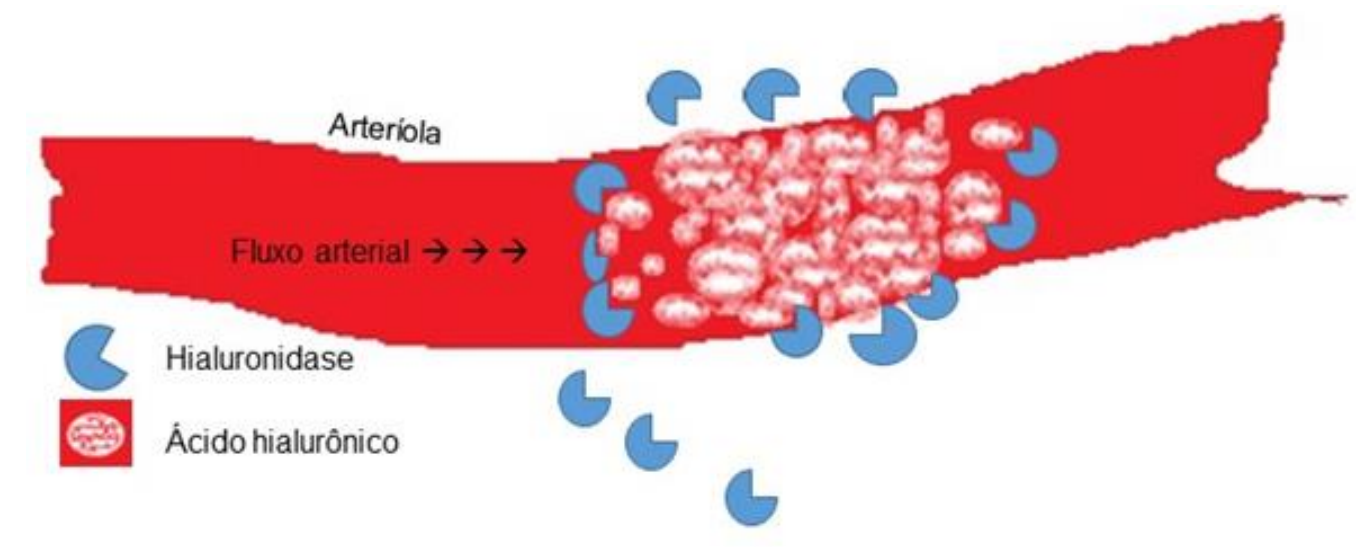

Fonte: BARBOSA KL, et al., 2021.

Figura 4 - Comparação ultrassonográfica: a) derme preenchida com ácido hialurônico (imagem anecoica (preta)) e b) degradação do ácido hialurônico após injeção de hialuronidase.

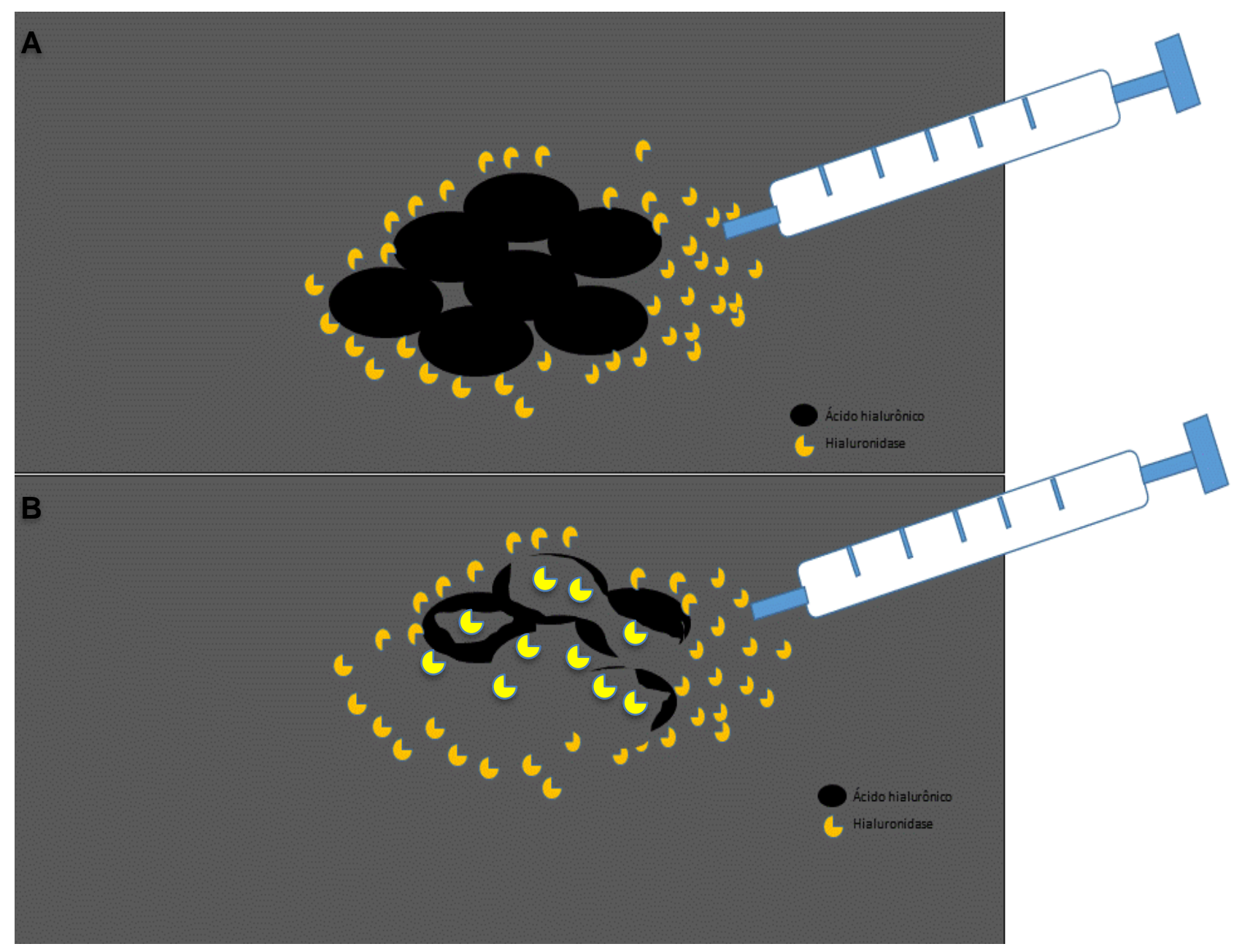

Fonte: BARBOSA KL, et al., 2021. 
O teste cutâneo de hipersensibilidade a hialuronidase consiste em aplicar 0,02 mL (3 UI) de $150 \mathrm{U} / \mathrm{mL}$ de solução da enzima por via intradérmica. $O$ teste positivo de sensibilidade mostra o desenvolvimento de uma pápula que aparece em até 5 minutos e podem durar 30 minutos. Por outro lado, o teste está contraindicado nos pacientes com processo inflamatório, uma vez que a hialuronidase aumenta a permeabilidade dos tecidos, causando nesse caso em específico, a propagação da infecção local, bem como em pessoas com alergia a picadas de abelha (KASSIR R, et al., 2011).

A aplicação de hialuronidase é recomendada em altas doses com intervalos de 1 hora de uma aplicação para outra. Sendo assim, para cada área isquêmica de $3 \times 3 \mathrm{~cm}$, são injetados $500 \mathrm{UI}$ de hialuronidase, seguida de massagem, compressa quente e monitoramento. A cada aplicação (1h em $1 \mathrm{~h}$ ) os sinais e sintomas são avaliados, e então o evento adverso - isquemia - é considerado contornado quando ocorre o desaparecimento total dos sinais e sintomas. Apesar dos tecidos se mostrarem aparentemente edematosos, a massagem suave na região deve ser estimulada uma vez que tenderá a diminuir o edema (DELORENZI C, 2017).

Um novo estudo experimental sobre a eficácia comparativa de diferentes doses e intervalo de tempo na administração da hialuronidase foi conduzido para tratamento da necrose de pele induzida por injeção de ácido hialurônico. Os experimentos revelaram que a injeção de $250 \mathrm{UI}$ de hialuronidase duas vezes com intervalo de 15 minutos, e a injeção de $125 \mathrm{UI}$ de hialuronidase quatro vezes em intervalos de 15 minutos, foram significativamente efetivos para reversão da oclusão com taxas de sobrevivência tecidual de 81,49 \% e $88,26 \%$, respectivamente. Portanto, este novo protocolo de administração de hialuronidase para correção das intercorrências vasculares parece proporcionar um melhor prognóstico quando se utiliza doses repetidas em um menor período de tempo, proporcionando mais rapidamente a degradação do ácido hialurônico, revascularização local, diminuição das sequelas e maior segurança ao paciente (LEE W, et al., 2019).

Apesar da eficiência da hialuronidase ser completamente incontestável, vale ressaltar que esta enzima tem atividade dependente do tempo, da dose injetada e da reticulação do ácido hialurônico injetado (TAYLOR GI, et al., 2017). A sensibilidade do ácido hialurônico para a degradação enzimática irá afetar a sua permanência no tecido, ou seja, quanto mais sensível for, mais rápido ocorrerá sua degradação (FLYNN TC, et al., 2013).

\section{Tratamento das complicações vasculares por ácido hialurônico}

A primeira escolha de tratamento para os casos de isquemia deve ser a injeção de hialuronidase. No entanto, quando a isquemia não é diagnosticada precocemente pelo profissional, evolui para casos mais graves, como, por ex., a necrose tecidual. A partir desta evolução importante, o uso de hialuronidade deve ser associado a outras terapias, que inclui a prescrição de Cefalexina $500 \mathrm{mg}$ 6/6h por 7 dias, Citrato de

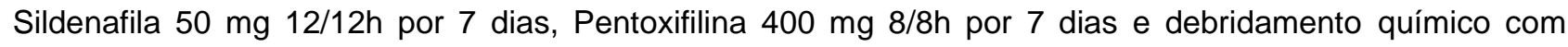
Dermacerium e sessões de oxigenoterapia hiperbárica (FURTADO GRD, et al., 2020).

A oxigenoterapia hiperbárica sistêmica é uma grande aliada no tratamento da necrose e os protocolos podem sofrer ajustes de acordo com a necessidade clínica. Para minimizar os danos aos tecidos moles afetados pode-se utilizar 2,8 de atmosfera absoluta durante 135 minutos na primeira sessão e 2,0 atmosfera absoluta durante 110 minutos por sessão até recuperação, tanto para estágio inicial como nos avançados (HONG WT, et al., 2019).

A prescrição de ácido acetilsalicílico de $100 \mathrm{mg}$ também deve ser considerada, uma vez que este fármaco em doses diárias na primeira semana pode evitar a formação de coágulos e juntamente com compressa quente e massagem vigorosa aumenta a vasodilatação dos vasos locais, proporcionando redução das sequelas ao paciente (DELORENZI C, 2014).

A implementação de protocolos de tratamento pode incluir Levofloxacina de $500 \mathrm{mg}$ a cada $24 \mathrm{~h}$ por 4 dias enquanto houver a presença de vesículas ou tecido necrótico para impedir a instalação de infecções oportunistas. Prednisona $25 \mathrm{mg} / 24 \mathrm{~h}$ por dia visando diminuir o edema e aumentar a microcirculação. Ácido acetilsalicílico $100 \mathrm{mg}$ como antiplaquetário, creme de Óxido de zinco 8/8h para melhorar a perfusão sanguínea e compressa com gaze e água morna (CIANCIO F, et al., 2019). 
O comprometimento visual ou cegueira é uma emergência médica que exige imediato atendimento do paciente por um oftalmologista. Nesse tipo de intercorrência o atendimento não pode ultrapassar 90 minutos, pois a recuperação visual é sensível ao tempo. A conduta deve ser iniciada com massagem ocular para reduzir a pressão intraocular e a injeção retrobulbar de hialuronidase (HWANG CJ e PERRY JD, 2018).

\section{Método de cânula guiada por ultrassonografia para injeção e degradação de ácido hialurônico}

O diagnóstico de ultrassom de alta frequência foi utilizado como uma ferramenta útil para obtenção de imagens não invasivas da pele e de tecido subcutâneo saudável ou patológico (GRIPPAUDO FR e MATTEI $M, 2011)$. Recentemente, seu uso foi expandido para o diagnóstico de acomodação de preenchedores permanentes e temporários em pacientes saudáveis (DE CABO-FRACÉS FM, et al., 2012; GRIPPAUDO FR e MATTEI M, 2011). O ultrassom de alta frequência permite avaliar a localização exata e o volume injetado do material preenchedor nos tecidos moles da face através do grau de absorção, esse diagnóstico é imprescindível para realizar um planejamento posterior nos casos de correções (QUEZADA-GAÓN N e WORTSMAN X, 2016).

O método de cânula guiada proporciona a visualização da cânula e do vaso sanguíneo (por meio do fluxo sanguíneo utilizando o Doppler), as imagens ultrassónicas captura em tempo real a região cujo procedimento está sendo realizado. Desta forma, a injeção intravascular de ácido hialurônico é evitada pelo mapeamento do sítio de inóculo da cânula. Este método confere maior segurança para os procedimentos em áreas de riscos (KUNIKATA $\mathrm{H}$, et al., 2015).

Graças ao ultrassom é possível verificar os estados isquêmicos em que se tem diminuição do fluxo sanguíneo arterial após as injeções de ácido hialurônico, bem como evitar e tratar os casos de necrose (NAKAGAMI G, et al., 2010). Deste modo, a cânula guiada por ultrassom é um método mais eficaz para manutenção do fluxo sanguíneo arterial e suporte de oxigênio para a pele e tecidos subcutâneos, fornecendo reconhecimento de área, evitando casos de injeção intra-arterial e compressão vascular subdérmica (IWAYAMA T, et al., 2018). O uso do ultrassom em injeções periorbitais deve ser estimulado, uma vez que a pele fina recobre o osso e os complexos ao seu redor tornam-se bastante desafiadores (GOLDBERG RA, 2005).

Muitos inquéritos estimulam a injeção de hialuronidase guiada por ultrassom para recuperação imediata do fluxo arterial. Muitos estudos nesse sentido são bastante inspiradores que aplicam a ultrassonografia para diagnóstico e tratamento imediatos das complicações vasculares com ácido hialurônico, reportando resultados impressionantes quanto à resolução do problema por meio da degradação do ácido seguido por melhora clínica e neutralização do espasmo (SCHELKE LW, et al., 2019).

Se o percurso do material preenchedor for um sistema vascular anastomosado, o material poderá ser desviado para outros ramos do vaso, promovendo um segundo sítio isquêmico (ASHTON MW, 2018). Alguns achados ultrassonográficos revelaram depósitos de ácido hialurônico na artéria labial com migração para artéria columelar (SCHELKE LW, et al., 2019). Por essa razão, o ultrassom de alta frequência é um poderoso aliado na detecção precoce de embolia vascular para evitar necrose. (WU S, et al., 2017).

O método guiado por ultrassonografia tem revelado satisfatória eficiência na aplicação de baixas doses de hialuronidase na degradação do ácido hialurônico em casos de intercorrências (embolização e compressão vascular, isquemia e necrose tecidual). O exemplo disto se refere à infusão de 35-60 UI de hialuronidase guiada por ultrassom que foi totalmente capaz de degradar um depósito de ácido hialurônico. Neste caso, menor quantidade da enzima provou ser capaz de degradar o ácido hialurônico, e isso se deve ao uso do ultrassom de alta frequência que funciona como um método de diagnóstico de material exógeno, revelando sua caracterização bem como a presença de complicações teciduais e de outros materiais de preenchimento estéticos (SCHELKE LW, et al., 2019; ADDOR F e NOGUEIRA S, 2016; WORTSMAN X e WORTSMAN J, 2011).

O ultrassom deve ser aplicado não somente em pacientes que demonstrem complicações de diferentes materiais de preenchimento, mas também quando se deseja excluir a coexistência de múltiplas substâncias de preenchimento, onde muitas vezes os pacientes não relatam na anamnese por desconhecimento, por não 
lembrar o uso deles, ou por não ser informado pelo profissional o que está sendo injetado. Nesse sentido, pode-se evitar a sobreposição entre os materiais absorvíveis e não absorvíveis e as complicações médicas (DÍAZ CPG, 2019).

\section{CONSIDERAÇÕES FINAIS}

Conhecimento da anatomia, planejamento individualizado, técnica correta de acordo com a reologia dos materiais, diagnóstico precoce e tratamento das possíveis complicações vasculares, isto é, compressão e embolização arterial, as quais podem evoluir para episódios de necrose e cegueira, faz com que procedimentos em harmonização facial tenham resultados previsíveis e eficientes. Atualmente, a inclusão do ultrassom como um exame utilizado no pré, trans e pós-operatório dos tratamentos estéticos estão intimamente associados ao sucesso da harmonização por se tratar de uma técnica rápida e confiável que mapeia e define a posição do sistema vascular e a localização do material preenchedor para degradação do ácido hialurônico nos casos obliteração e compressão vascular.

\section{REFERÊNCIAS}

1. ADDOR F, NOGUEIRA, S. Injectable polyethylene glycol gel as dermal filler: 01 year clinical and ultrasound followup. Journal of Clinical \& Experimental Dermatology Research, 2016; 7(2): 1-7.

2. ASHTON MW, et al. The Role of Anastomotic Vessels in Controlling Tissue Viability and Defining Tissue Necrosis with Special Reference to Complications following Injection of Hyaluronic Acid Fillers. Plastic and Reconstructive Surgery, 2018; 141(6): 818-830.

3. BELEZNAY K, et al. Avoiding and treating blindness from fillers: a review of the world literature. Dermatologic Surgery, 2015; 41(10):1097-1117.

4. BRAVO BSF, et al. Delayed-type Necrosis after Soft-tissue Augmentation with Hyaluronic Acid. The Journal of Clinical and Aesthetic Dermatology, 2015; 8(12): $42-47$.

5. CIANCIO F, et al. Early Hyaluronidase Use in Preventing Skin Necrosis after Treatment with Dermal Fillers: Report of Two Cases. F100 Research, 2019; 7(1388): 1-11.

6. DE CABO-FRANCES FM, et al. Ecografía de los materiales de relleno inyectables y su interés en el seguimiento diagnóstico. Cirurgía Plástica Ibero-Latinoamericana, 2012; 38(2):179-187.

7. DELORENZI C. New High Dose Pulsed Hyaluronidase Protocol for Hyaluronic Acid Filler Vascular Adverse Events. Aesthetic Surgery Journal, 2017; 37(7): 814-825.

8. DELORENZI C. Transarterial Degradation of Hyaluronic Acid Filler by Hyaluronidase. Dermatologic Surgery, 2014; 40(8): 832-841.

9. DÍAZ CPG. High Resolution Ultrasound of Soft Tissues for Characterization of Fillers and Its Complications. Colombian Journal of Radiology, 2019; 30(1):5064-5068.

10. FLYNN TC, et al. Molecular Weight Analyses and Enzymatic Degradation Profiles of the Soft-Tissue Fillers Belotero Balance, Restylane, and Juvéderm Ultra. Plastic and Reconstructive Surgery, 2013; 132(4): 22-32.

11. FURTADO, GRD, et al. Necrose em Ponta Nasal e Lábio Superior após Rinomodelação com Ácido Hialurônico relato de caso. Aesthetic Orofacial Science, 2020; 1(1): 62-67.

12. GOLDBERG RA. The Three Periorbital Hollows: A Paradigm for Periorbital Rejuvenation. Plastic and Reconstructive Surgery, 2005; 116(6): 1796-1804.

13. GRIPPAUDO FR, MATTEI M. The Utility of High-Frequency Ultrasound in Dermal Filler Evaluation. Annals of Plastic Surgery, 2011; 67(5): 469-473.

14. HONG WT, et al. Minimizing Tissue Demage Due to Filler Injection with Systemic Hyperbaric Oxygen Therapy. Archives of Craniofacial Surgery, 2019; 20(4): 246-250.

15. HWANG CJ, PERRY JF. Filler Complications. Advanced Cosmetic Surgery, 2018; 1(1): 143-150.

16. IWAYAMA T, et al. Ultrasonography-guided Cannula Method for Hyaluronic Acid Filler Injection with Evaluation using Laser Speckle Flowgraphy. Plastic and Reconstructive Surgery, 2018; 6(4): 1-3.

17. KASSIR R, et al. Extensive necrosis after injection of hyaluronic acid filler: case report and review of the literature. Journal of Cosmetic Dermatology, 2011; 10(3): 224-231.

18. KIM MS, et al. Allergic reaction to hyaluronidase use after hyaluronic acid filler injection. Journal of Cosmetic \& Laser Therapy, 2015; 17(5): 283-285.

19. KOH IS, LEE W. Filler Complications: Filler-Induced Hypersensitiity Reactions, Granuloma, Necrosis, and Blindness. Springer. (eBook). 2019.

20. KOHN JC, et al. Dynamic high-resolution ultrasound in vivo imaging of hyaluronic acid filler injection. Dermatologic Surgery, 2013; 39(11): 1630-6. 
21. KUNIKATA H, et al. Relationship of ocular microcirculation, measured by laser speckle flowgraphy, and silent brain infarction in primary aldosteronism. PLoS One. 2015; 10(2):1-12.

22. LEE W, et al. Comparative Effectiveness of Different Interventions of Perivascular Hyaluronidase. Plastic and Reconstructive Surgery, 2019; 145(4): 957-964.

23. LIMA VGF, et al. External vascular compression by hyaluronic acid filler documented with high-frequency ultrasound. Journal of Cosmetic Dermatology, 2019; 18(6):1629-1631.

24. MICHEELS $P$, et al. Ultrasound and histologic examination after subcutaneous injection of two volumizing hyaluronic acid fillers: A preliminary study. Plastic and Reconstructive Surgery, 2017; 5(2): 1-8.

25. MUNDADA $P$, et al. Injectable facial fillers: imaging features, complications, and diagnostic pitfalls at MRI and PET CT. Insights into Imaging, 2017; 8(6): 557-572.

26. NAKAGAMI G, et al. Evaluation of the usefulness of skin blood flow measurements by laser speckle flowgraphy in pressure-induced ischemic wounds in rats. Annals of Plastic Surgery, 2010; 64(3): 351-354.

27. QUEZADA-GAÓN N, WORTSMAN X. Ultrasound-guided hyaluronidase injection in cosmetic complications. Journal of the European Academy of Dermatology and Venereology, 2016; 30(10): 39-40.

28. SCHELKE LW, et al. Early ultrasound for diagnosis and treatment of vascular adverse with hyaluronic acid fillers. Journal of the American Academy of Dermatology, 2019; 19(3):2392-2398.

29. SCHELKE LW, et al. Use of ultrasound to provide overall information on facial fillers and surrounding tissue. Dermatologic Surgery, 2010; 36(3):1843-1851.

30. SCHWENN OK, et al. Experimental Percutaneous Cannulation of the Supraorbital Arteries: Implication for Future Therapy. Investigative Ophthalmology \& Visual Science, 2005; 46(5): 1557-1560.

31. TAYLOR GI, et al. The functional angiosomes clinical implications of the anatomical concept. Plastic and Reconstructive Surgery, 2017; 140(4): 721-733.

32. TOWNSHEND A. Blindness After Facial Injection. The Journal of Clinical Aesthetic Dermatology, 2016; 9(12): 5-7.

33. VAN LOGHEM JAJ, et al. Sensitivity of Aspiration as a Safety Test before Injection of Soft Tissue Fillers. Journal of Cosmetic Dermatology, 2017; 17(1): 36-46.

34. VEDAMURTHY M, VEDAMURTHY A. Dermal fillers: Tips to achieve successful outcomes. Journal of Cutaneous and Aesthetic Surgery, 2008; 1(2): 64-67.

35. WORTSMAN X. Common applications of dermatologic sonography. Journal of Ultrasound in Medicine, 2012; 31(1): 97-111.

36. WORTSMAN X, WORTSMAN J. Sonographic outcomes of cosmetic procedures. Amedrin Journal of Roentgenology, $2011 ; 197(5):$ 910-918.

37. WU S, et al. Anatomic Study of Ophthalmic Artery Embolism Following Cosmetic Injection. Journal of Caniofacial Surgery, 2017; 28(6): 1578-1581. 